\title{
Counting the cost: coping with tariff increases amidst power supply shortfalls in urban households in Ethiopia
}

Meron Tesfamichael $^{1}$, Yacob Mulugetta ${ }^{1}$, Abebe D. Beyene ${ }^{2}$, Samuel Sebsibie ${ }^{2}$

\begin{abstract}
Although affordability is important, people do not need to be money poor to experience energy deprivation. This paper examines how an electricity tariff increase affects household energy consumption by situating the price change within the broader context of energy service provision in Ethiopia. We place households' lived experience in interaction with the institutional and infrastructural dynamics that constitute the energy sector in Addis Ababa to observe how the price increase intersects with service provision. Since the tariff increase was implemented, households have changed their daily routines to control cost. Our findings show that energy consumption behaviour is also shaped by service-related inadequacies (unreliable supply and frequent power outages). However, families coping capacity (to the tariff increase and power supply shortfalls) is undermined by an energy market that is rife with information asymmetries and uncertainties. Thus, although socioeconomic factors underpin the energy insecurity households experience, inadequate supply, and diminishing confidence in service providing institutions appears to heighten their vulnerability. The paper argues that while the price change has an overall effect on consumption, its impact needs to be seen within the context of its systemic interaction with the broader energy governance and service delivery challenges.
\end{abstract}

\footnotetext{
${ }^{1}$ Department of Science, Engineering, Technology \& Public Policy, University College London, Shropshire House, 11-20 Capper Street, London WC1E 6JA, United Kingdom

${ }^{2}$ Environment and Climate Research Center (ECRC), Policy Studies Institute (PSI), Addis Ababa, Ethiopia
} 


\section{Introduction}

In a developing countries' context, there are a number of reasons why a grid-connected household might not be able to secure an adequate level of energy services. Although affordability is an important factor, people do not need to be money poor to experience energy deprivation. There is growing consensus that energy poverty cannot be reduced to monetary metrics only [1], as well as that how households access and use modern energy is mediated by a range of factors, including the provision of energy and the suitability as well as reliability of the available technology, among other things $[2,3]$. Hence, to be energy poor is to be in a situation where an individual or a community is unable to realise essential capabilities as a result of insufficient access to affordable, reliable and safe energy services [4]. This follows the approach which diagnoses energy deprivation from the perspective of the energy services accessed and achieved, and looks not at the amount of energy consumed, but what is actually 'usefully delivered' [4,5].

'Energy service' entails a multifaceted process that requires the alignment of a complex network of activities, infrastructures and resources, as well as institutional dynamics that operate across multiple sites and beyond the confines of a home [6-8]. As a concept it has been useful in shifting the focus away from the supply of fuels onto the benefits energy carriers produce for human wellbeing [5,9]. Energy service as an approach also highlights that the utility of energy delivery in the home is dependent on subjective variables, and that it is important to take the wider environmental, cultural, technical and political factors into account [10-12]. In this regard, energy service and the relational approach it draws from has been used to argue the importance of good governance and the role of 'systems and infrastructures of provision' in contributing to the rise of domestic energy poverty [12]. Bouzarovski and Petrova recast energy poverty as 'energy service poverty' [13] to capture the range of factors that contribute to inadequate domestic energy provision. In discursive terms, energy service poverty serves as a call for a context specific approach to ensuring 'an adequate match between energy resources, technical infrastructures and household needs' $[12$, p. 16]. Seen in such ways, the concept of energy services also broadens the unit of analysis by combining the wellbeing aspects of access with quality of service delivery and its governance [8]. 
With energy service poverty as a descriptor of a state within a certain temporal setting, the concept of energy vulnerability is useful in highlighting the conditions leading to such circumstances. 'Energy vulnerability' is the term used to capture the factors that contribute to households experiencing a socially and materially inadequate level of energy services [14]. Although the wellbeing households achieve from accessing modern energy services is dependent on subjective variables, their state of vulnerability can also be exacerbated by the persistent deficiency of energy provision, and as a result of decisions and mechanisms operating elsewhere in the energy system $[10,15]$. While access and affordability remain key factors, public policies and bureaucratic decisions have an effect on whether (and how) particular groups of households experience a socially and materially inadequate level of energy services $[13,14,16-18]$. It is, for instance, well documented that consumers' relationships with and perception of utility companies affect their likelihood of experiencing inadequate energy services [19-22]. Hence, although energy poverty can be attributed to a range of institutional, policy and sociodemographic processes, to understand how the problem is manufactured it becomes necessary to delve deep into the nature of the relationships among them [23].

This paper has two objectives: to examine the effect of the latest tariff increase on households' energy consumption behaviour in Ethiopia; and, to situate the tariff increase within the broader context of domestic energy provision. Relying on a questionnaire-based survey and focus group discussions carried out with households in Addis Ababa, the capital city of Ethiopia, we argue that while the tariff change has an overall effect on how households consume electricity, its impact on behaviour and wellbeing cannot be seen in isolation from the inadequate system and infrastructure of provision. We place the tariff increase within the context of its systemic interaction with the broader governance and service delivery challenges. This builds on the logic that the lived experience of the consumer needs to be seen as a condition that arises from the ways in which the institutional, infrastructural and individual biographies of households have been drawn together into a networked configuration $[2,24]$.

The research was carried out 10 months after the tariff change became effective, with an objective to observe its impact on consumers' behaviour. We started with the question of how the tariff increase has affected consumers' behaviour. However, it soon became clear to the team that the tariff change is one aspect of the multiple and interconnected energy related 
challenges people face. Discussions about cost appear inseparable from issues like accessibility, reliability, accountability and households' insufficient understanding, which then impacts their coping capacity. Discussions around households' coping strategies also revealed another dimension to the barrier people face, i.e. the relationship users have with the service providing institutions. As we argue, households' capacity to assess and mitigate their situations is undermined by an energy market that is rife with information asymmetry. Considering these factors and the recognised interconnected nature of households' lived experience, we widen the scope of the research and place the tariff increase within the overall systems of provision and governance of service.

The rest of the paper is organised as follows: in the next section (Section 2), we outline the conceptual framework within which we are developing this paper. In Section 3, we introduce the research context and the methodological approach we have taken. We discuss our findings in Section 4 and over three sub-sections (sub-section 4.1, 4.2, 4.3). First, we survey the needs and wants households satisfy by accessing modern energy services. Second, we review the energy service related challenges households experience. We pay attention to the impact of frequent power outages and consumers' relations with the service providing institutions to uncover the hidden costs and consequences of inadequate systems of provision. Third, we observe how the 2018 tariff increase is affecting energy consumption behaviour and the coping strategies families adopt. We conclude the paper in Section 5 with a call for intervention efforts to be grounded in an assessment that combines household-level circumstances with structural constraints.

\section{Conceptual framework}

There is a consensus that energy poverty - or a situation in which a household is unable to access a socially and materially necessitated level of energy services - is not commensurate with income poverty $[3,16,24]$. With access to clean and modern energy services seen as central to socio-economic wellbeing, there is also growing interest in the provision of energy services $[2,3,24]$. In this regard, 'energy services' is used to highlight the utility or the application of useful energy to tasks desired by the end user [25]. A modern energy service is valued for the products and services it enables people to access as well as for its contribution to their wellbeing in its broadest sense, whether it be a well-lit room, a cooked meal, motorised mobility, mechanical power, information and communication, entertainment, space cooling and heating, or refrigeration [5,26-29]. Subsequently, shifting the focus to the 
actual benefits energy delivers, the energy services approach is also useful in framing energy deprivation as a constraint on people's ability to access certain material goods, assets, capabilities and opportunities [25]. This draws from the Capability Approach, in which capability is defined as the possibility to live a good life as defined by the persons themselves in a reasonable way given their context of life [30]. Building on this, Day et al. [4] define energy poverty as 'an inability to realise essential capabilities' and argue that 'consumption of energy services should be understood as linked to the quest for certain capabilities' (p. 259 $-260)$.

Although the energy related wellbeing that households can achieve varies between societies and depends on other subjective variables, how people experience access cannot be separated from the technologies, institutions and infrastructures that constitute the systems of provision $[10,13,23]$. Thus, by putting the emphasis on what people 'need and want', energy services becomes fundamentally about the quality, reliability and affordability of the service delivered $[4,25,29,31]$. Seen this way, energy services also entails an alignment of a complex network of activities, infrastructures and resources, including the institutional dynamics and material input surrounding production, distribution and consumption [6,8]. Material input refers to the infrastructure that performs the energy conversion, the networks that carry the energy to homes and the artefacts that enable households to perform tasks [8]. Institutional dynamics encompasses the policies, procedures and (formal and informal) processes that organise the network of activities, as well as historically embedded norms and power structures, that regularise how energy services are delivered. In this case, the formulation and implementation of public policies at different scales of governance could potentially form the institutional basis for a rise in domestic energy deprivation in a given context [24]. In other words, the wellbeing aspect of access to modern energy services needs to be examined in light of how the institutional, infrastructural and individual biographies of households are drawn together to enable or hinder end users to flourish within them [2,8,32]. In this paper we use the relational approach to situate the energy deprivation households in Addis Ababa experience within a networked space defined by the relationships between households' everyday energy needs, the infrastructures that deliver the service and the institutions that govern the process $[23,24]$. The relational aspect points to the fact that in the face of [a] networked relationship', individuals' conservation and coping behaviour are not necessarily enough [2, p. 958]. 
Energy services as a multifaceted process that operates across multiple sites draws attention to the wider political and institutional processes that shape the factors that render some households and communities vulnerable to energy poverty [33]. As a concept energy vulnerability, which refers to the propensity of a household to experience an inadequate level of energy services, has been relevant in highlighting the conditions that contribute to domestic energy deprivation [13]. For instance, Middlemiss [34,35] looks at tenancy relations, energy cost, income stability and social relations to observe how changes in either one of these factors, or in the relationship between them, can increase a household's energy vulnerability. Others point out that how utilities choose to price energy plays a role in determining whether a household is likely to live in conditions of domestic energy deprivation. Bouzarovski and Thomson [16] attribute the rising incidence of household level energy poverty in Eastern and Central Europe to a sector reform that saw the rise of energy tariffs without the development of adequate social welfare and energy efficiency mechanisms. Bureaucratic decisions and how organisations prioritise tasks can also increase the probability of some households experiencing inadequate energy services. In their study of infrastructure resilience (i.e. the speed with which functions are restored after a power outage) in the United States, Liévanos and Horne [17] observe that low income communities experience longer power outage durations than affluent neighbourhoods due to the utilitarian bureaucratic procedure companies apply to power restoration. The authors note that because utilities are not required to monitor how power outage duration is correlated with neighbourhoods' socioeconomic status, the inequality in service provision persists.

How institutions choose to capture and measure access to energy services could also hide the underlying vulnerability some communities face. In urban areas, access to electricity is often treated as a homogenous process, where the presence of a grid is seen as akin to universal access. However, this representation of access masks the energy challenges urban households face on daily basis such as unreliable service, hazardous infrastructure, affordability and other insecurities related to tenure issues [36-38]. In Mozambique, Castán Broto et al. [39] observe that while the electrification figures for Maputo are higher than for the rest of the country, the numbers conceal many contingencies in the supply, including varying rates of connection. Finally, although deliberate sociotechnical transitions often imply a move towards a socially desirable end-state, technological changes also expose some communities to energy deprivation. For instance, a prepaid meter that is commended for 
enabling households to have control over their consumption is also seen to further entrench energy poverty among lower income households [40,41].

Moreover the (energy) vulnerability some households experience is partly shaped by their relationship and attitudes towards service providing institutions. Studies note that a household's attitude towards the service provider plays a role in influencing their energy related decisions [19-22]. In South Africa, Fjeldstad [19] observes that the level of confidence people have in the utility's ability to provide expected services influences their compliance in paying their bills. In Zanzibar, Winther [22] notes that households' limited competence to monitor whether institutional procedures are fair affects their overall confidence in the utility. As we also argue in this paper, asymmetric information between service providing institutions and end-users not only means consumers are making suboptimal energy related decisions, but also that it fuels their innate distrust towards the service provider. Subsequently, interaction with the utility is not only fraught with tension, but also increases vulnerable households' propensity to adopt extreme coping mechanisms that could lead to other health and social problems [34]. With this as the backdrop, a closer look into moments of tariff increase and service disruptions reveals the tension between infrastructures of supply, the cultures of consumption and coping amongst users, and the politics surrounding regulation, repair and maintenance [42].

\section{Research context, design and methodology}

Committed to becoming a middle-income country by 2025 , in the last two decades Ethiopia has been making significant efforts to accelerate economic growth through large scale public investments in infrastructure, industrial parks, the redevelopment of urban areas, and power generation capacity. Although the national development strategy acknowledges the private sector as a key player in the economy, with most of the economic project governmentfinanced, a private-sector led market system remains underdeveloped [43]. Liberalisation mostly meant reconfiguration of how sectors operate, otherwise, the state continued to pay an essential role in all major economic sectors including the energy sector. Ethiopia has a strong portfolio of pro-poor interventions, including fee waiver schemes covering health expenses in both rural and urban areas, as well as a safety net programme that reaches eight million in rural areas with unconditional and conditional cash transfers. However, researchers also observe that poverty reduction and the presence of the state in the economy have not involved democratic and open participation in the development process or in policy making $[44,45]$. 
Although Ethiopia has a federal system, decisions regarding public development projects take a top down and highly centralised approach with little consultation and without the participation of the public and other stakeholders [46]. Public service delivery suffers from capacity and lack of transparency, accountability and responsiveness. The culture of direct accountability of service providers to citizens is also at its infancy [47].

Over the past two decades, Ethiopia has made significant investments to increase access to electricity and enhance its power generation capacity. Progress in this area was made through a policy that focused on the development of large-scale hydropower plants. From 1991 to 2019, the country's power generating capacity increased from $380 \mathrm{MW}$ to $4260 \mathrm{MW}$. The construction of the Grand Ethiopian Renaissance Dam (GERD), Africa's largest, promises to double current generation capacity. The Dam, which is funded by the government through domestically issued bonds, is expected to make Ethiopia the largest exporter of power in Africa. The National Electrification Programme (2019) has set the goal of achieving universal electrification by 2025 .

However, there is a paradox in this picture. Despite rapid growth at the supply end, access to electrification at the household level is low. According to the World Bank's Multi-Tier Framework (MTF), only 44 per cent of all households have access to basic electricity supply, while 56 per cent of households have no access [48]. The study also notes that 38 per cent of the unelectrified households are located within 7 kilometres of the national grid and report administrative barriers or delay as the main reason for not having a grid connection. Those with grid connection also experience frequent and long hours of power outages [48,49]. The MTF survey shows that over 55 per cent of grid connected households face power disruption 4 to 14 times in a week [48]. According to an earlier survey (the World Bank Enterprise Survey, 2015), in Ethiopia power outages occur 8 times in a typical month, each with an average duration of 5.8 hours. The key reason behind the frequent power outages is the poor physical condition and low capacity of the transmission and distribution lines, as well as a shortfall in supply and scheduled outages [49].

Alongside the capital investment in generation capacity, the energy sector has also been undergoing a restructuring process to improve the financial strength of the sector and untangle the state from direct economic engagement with it. In 2013, the Ethiopian Electric Power Corporation was split into two public companies: the Ethiopian Electric Power, in 
charge of generation and transmission; and the Ethiopian Electric Utility, responsible for distribution. Revenue collection was outsourced through a public-private partnership and a prepaid metering system was introduced with the aim of (eventually) ending reliance on a monthly door-to-door meter reader. The restructuring incorporates corporate principles or a market-based approach to improve operational efficiency and cost recovery. On the one hand, with the entire electricity supply chain under the direct ownership of the state, the government continues to play a critical role in how citizens experience electricity related services. On the other, the 'staying in, but keeping out' [50, p. 376] approach that was accomplished through the sector restructuring meant that although the government remains in the business of delivering energy services, as a legally separated entity, the sector flexibility was enhanced.

Compared to neighbouring countries in East Africa, Ethiopians have been enjoying low electricity tariffs for a long time. However, this also meant that the utility company operates at a loss. Over the years, as the gap between the electric supply cost and the cash collected widened, it resulted in depletion of profits and the rise of public debt [51]. For instance, recently, the Minister of Water, Irrigation and Electricity told reporters that earnings of 7 billion Ethiopian birr (US\$253 million) in 2017 were significantly lower than the 28 billion Ethiopian birr (US\$101 billion) needed to cover the costs associated with the generation and distribution of electricity [52]. Hence, burdened with large debt, in 2018 the government partly with the aim of sending a price signal to private investors and partly driven by the need for revenue recovery - revised the tariff rate structure. The revised electricity tariff was announced by the Utility company, which stated that the revision as necessary to meet energy demand. The tariff reform is also in line with the reform schedule agreed under the World Bank Development Financing Triggers [43] The change included an incremental increase in tariff rates over four years: a minor increase for the first 12 months, followed by a progressively steeper annual increase until 2022. The policy also introduced a change in how consumption would be calculated, from an increasing block tariff (IBT) to a volume differentiated tariff (VDT) structure [53]. The shift from IBT to VDT effectively withdrew subsidies for all groups of consumers except for those consuming below $50 \mathrm{kWh}$, for whom the tariff remained unchanged. Under the VDT, if the monthly consumption exceeded the 50 $\mathrm{kWh} /$ month threshold, all consumption must be paid for at an unsubsidised and much higher rate. 
In Ethiopia, under the current tariff structure, the change in price is significant and punitive. For low income households the penalty for consuming over $50 \mathrm{kWh}$ is high not only because of the doubling of the cost per unit (between the first and the second block), but also due to a significant change in how the service charge is calculated and priced. Under the current tariff structure, households that consume below $50 \mathrm{kWh}$ are charged 10 Ethiopian birr (US\$ 0.34), while households that consume over $50 \mathrm{kWh} / \mathrm{month}$ are charged 42 birr (US\$ 1.45) (see Table 1). According to the authors' calculations, a family consuming $200 \mathrm{kWh}$ per month would have paid 96 Ethiopian birr (US\$3.31); as of December 2019, the same family's monthly bill would have risen to 254 Ethiopian birr (US\$8.80). ${ }^{1}$

Table 1: Tariff calculation.

\begin{tabular}{|l|l|l|l|l|l|l|}
\hline \multirow{2}{*}{ Electricity consumption } & \multicolumn{5}{l|}{ Monthly bill before 2018 (in Eth. birr) } & \multicolumn{3}{l|}{ Monthly bill in 2019 (in Eth. birr) } \\
\cline { 2 - 7 } & Cost & Service charge & Total & Cost & Service charge & Total \\
\hline $50 \mathrm{kWh} /$ month & 13.65 & 3.40 & 17.05 & 13.65 & 10.00 & 23.65 \\
\hline $51 \mathrm{kWh} /$ month & 18.18 & 6.82 & 25.00 & 28.65 & 42.00 & 70.65 \\
\hline
\end{tabular}

Source: Authors' calculation

This paper draws on research carried out in Addis Ababa, the capital city of Ethiopia. Over the last two decades, Addis Ababa has been the recipient of high public investment in urban renewal and redevelopment projects. As a result, the city has experienced high rates of economic growth [54]. Notwithstanding the strong economic trend, Addis Ababa also faces significant challenges. Unemployment is estimated at 23.5 per cent, and one in four households reports an unemployed adult [55]. Furthermore, only 44 per cent of the population has access to clean water, and less than 30 per cent has access to sewerage services [54]. With 99.9 per cent of households connected to the grid, almost all households in Addis Ababa are said to be connected to the grid. According to the World Bank MTF survey, which was carried out two years before the latest tariff increase, the average electricity consumption in Addis Ababa is $193 \mathrm{kWh}$ per month [48]. Power outages and service interruptions are major sources of dissatisfaction. The ageing electricity network is overloaded and unable to provide efficient service. In a typical month, households in the city experience power outages seven times, with an average duration of six hours [56]. In the survey we carried out for this study, 26 per cent of the participants said they experience more

\footnotetext{
${ }^{1}$ At the time of the survey, the exchange rate was $1 \mathrm{USD}=28.98$ ETB. Note also that the service charges for owners of prepaid and postpaid meters are different. For the sake of simplicity, we assume that customers use postpaid meters. The latest tariff can be accessed and viewed online - the Ethiopian Electric Utility website www.eeu.gov.et
} 
than six power outages in a week, while 40 per cent said they experience up to four power outages in a week. For more on households' energy consumption behaviour in Addis Ababa and prior to the tariff change, see $[48,49,57,58]$.

\subsection{Research design and methodology}

Research was conducted in four of the 10 sub-cities in Addis Ababa: Ledeta; Kirkos; Gulele; and Yeka. The sub-cities were selected on purpose to represent the diverse socioeconomic status of residents of the city. In selecting the sub-cities, socioeconomic indicators such as population density, housing conditions, location, employment status and distribution of the sub-cities' populations by expenditure quintile were considered. In terms of population density, Lideta is among the most densely populated while Yeka is relatively sparsely populated. Lideta and Kirkos are represent the interior and older part of the city. Yeka and Gulele are bordering the city, with the nearest peri-urban areas. A higher proportion of the population in Gulele and Kirkos is engaged in various economic activities as opposed to Lideta, which has the highest unemployment rate. In addition, a higher proportion of the population in Yeka and Kirkos tends to be within the higher per capita expenditure quintiles, as opposed to Lideta [59].

Data were collected using a combination of a questionnaire-based survey and focus group discussions (FGDs). Participant recruitment followed the following procedure: from each sub-city, customers were randomly picked from the EEU's database of customers and were contacted via a phone call. The research team contacted a total of 100 households and invited them to join us for a meeting. Of the 100 households we contacted, 53 agreed to participate in the study. Once they agreed, appointments were scheduled for the next day. On the day, before the FGD started, participants were asked to fill in a questionnaire survey. This was then followed by FGD that lasted from 90 minutes to two hours. The research team carried out eight FGDs - two FGDs per sub-city, one in the morning and another in the afternoon. In each session six to eight individuals participated. FGDs were carried out in the local language, Amharic, and, subsequently, translated into English for coding. Coding was carried out on two levels. The first level (descriptive coding) aimed to identify patterns and themes, while the second level (analytic coding) focused on identifying the logical linkages between themes [60]. 
The participants represented households with a wide range of socioeconomic and demographic backgrounds. With the youngest participant 19 years old and the oldest participant 74 , the average age was 42 . Around 38 per cent of the participants were female and the rest were men. Around 34 per cent hold a first degree or diploma, and 44 per cent of them completed secondary school. Out of the 53 participants, 34 (64 per cent) said they were married. Except for three, all reported having at least one income earner in the house. The majority of the primary earners (52 per cent) are self-employed, while 30 per cent identified as government employees. Over 60 per cent of the participants said they have lived in their current residence for over 15 years.

Research limitations: The case study we present here is by no means representative of the city population. For instance, because we relied on the EEU's customer database to recruit participants, our sampling is limited to primary metered customers. Thus, nonprimary consumers who rely on secondary connections are underrepresented in our study. Of the 53 households we sampled, only three rely on a shared meter. However, in reality, a significant number of households in Addis Ababa access electricity through shared meters as tenants. According to the National Welfare Monitoring survey in the city, for every household with a private account, there is one self-identified nonprimary customer sharing a metered connection [55].

\section{Findings and discussion}

In the subsequent three sub-sections, we will discuss our findings under three broad themes: sub-section 4.1 explores what needs and wants households are trying to satisfy by seeking and accessing modern energy services; sub-section 4.2 investigates the quality and supply of electricity provision in Addis from a perspective of consumers' wellbeing; and sub-section 4.3 discusses the impact of tariff change on household energy consumption behaviour and raises the question of who is affected the most. We observe how the price increase and provision of service intersect and increase the likelihood of some experiencing energy deprivation.

\subsection{The usefulness of modern energy services}

In Addis Ababa, energy consumption patterns have changed with income. As noted earlier, Addis Ababa is urbanising at a rapid rate and has experienced significant economic growth in recent years. Between 2006 and 2016, the percentage of residential areas occupied by high- 
rise condominiums (four floors or higher) increased from 1 per cent to 11 per cent. Within the same period, the percentage of residential land occupied by single family housing increased from 5 per cent to 25 per cent [61]. This dramatic increase represents a transformation of the city landscape and reflects the rise in economic prosperity for many residents. It also suggests an increase in the use of modern kitchens, where electrical appliances are more convenient and can provide services that were once provided by traditional fuel [62]. Western inspired architectural design also play a role in dictating how families conduct their affairs, entertain themselves and weatherise their homes $[29,63]$.

In this section, we observe what role electricity plays in the lives of those we interviewed. We use energy related routines and material cultures [10] as a surrogate to observe how modern energy is interwoven into the city way of life. The distinctions we draw here are artificial and need to be seen in the context of evolving energy services and service demands. The grouping is not meant to suggest there is a clear difference between households based on socioeconomic characteristics, but as a demonstration of how energy demands and expectations, as well as the notion of what constitutes an urban way of life, is evolving.

Based on the survey of appliances households own, we identified three categories of benefits and services households in Addis Ababa seek to perform and achieve by consuming electricity. The first category represents appliances used for illumination, communication, cooking, preserving and entertainment. The appliances under this category include bulbs, refrigerators, televisions, satellite dishes, electric stoves, mobile phones and radios. The study participants overwhelmingly agree that these are the benefits they seek on a daily basis. The benefits that are associated with lighting are many and extend to ensuring safety, security and psychosocial wellbeing. A charged mobile phone represents the ability to maintain contact within one's social network. Depending on household size, participants reported owning at least one, and at most eight, mobile phones. Those who are self-employed, partake in the informal economy or are currently seeking employment noted that a mobile phone is an important lifeline. Entertainment devices are wildly popular and are associated with psychosocial wellbeing. The wider ownership of mobile phones, refrigerators and televisions also appears to be related to the lack of obvious substitutes for these appliances. The fact that these appliances, including electric stoves, are widely used across all income groups also suggests that their acquisition is weakly dependent on socioeconomic status. 
The second category represents electrical appliances with benefits that are commonly associated with convenience, comfort and cleanliness $[29,64]$. The appliances under this category are used to save time (food processors, kettles, bread toasters, washing machines), enhance communication and access to information (computers), and maintain personal grooming and hygiene (irons, hair clippers and hair driers). Relative to the previous category, appliances in this category are owned by fewer households and offer a clear indication of the evolving nature of demand, attitudes and consumers' expectations about modern energy services. Appliances in this category are also popular and sought after by households that currently do not own one. Asked what electrical appliance households aspire to acquire next, the majority ( 68 per cent) said a washing machine, followed by a refrigerator, an iron, a food processor and a microwave.

The third category of appliances, which we are referring to as 'luxury goods and services, is owned by a minority of the study participants. These are higher load appliances and tend to go the extra step to add comfort and indulgence to daily household routines and the general atmosphere of the home (e.g. water heater, cooling fan, space heater, home decoration lighting, video games, microwave). High load appliances are generally less common in Ethiopia. For instance, if we take water heaters, which are generally classified as high load appliances, only six of the 53 participants own one. This suggests that the households mainly use traditional fuels or electric stoves to heat water. Similar findings were reported by the World Bank's MTF, which treats water heater as an appliance that require Tier-5 (over 2000 watts) capacity [48].

Table 2. Household appliance ownership

\begin{tabular}{|c|c|c|}
\hline Category & Appliance & $\begin{array}{l}\text { Ownership } \\
\text { (per cent) }\end{array}$ \\
\hline \multirow{6}{*}{$\begin{array}{l}\text { Basic goods and } \\
\text { services }\end{array}$} & Television & 98 \\
\hline & Mobile phone & 99 \\
\hline & Electric baking stove (mitad) $)^{2}$ & 87 \\
\hline & Refrigerator & 81 \\
\hline & Electric stove & 79 \\
\hline & Radio & 62 \\
\hline \multirow{8}{*}{$\begin{array}{l}\text { Convenience and } \\
\text { comfort goods and } \\
\text { services }\end{array}$} & Computer & 40 \\
\hline & Food processor & 30 \\
\hline & Iron & 28 \\
\hline & Tea kettle & 26 \\
\hline & Music set & 25 \\
\hline & DVD player & 21 \\
\hline & Washing machine & 19 \\
\hline & Bread toaster & 19 \\
\hline
\end{tabular}

\footnotetext{
${ }^{2}$ mitad is a baking appliance used to make injera, a local staple food
} 


\begin{tabular}{lll}
\hline & Hair clipper & 19 \\
\cline { 2 - 3 } $\begin{array}{l}\text { Luxury goods and } \\
\text { services }\end{array}$ & Hair drier & 17 \\
\cline { 2 - 3 } & Coffee grinder & 13 \\
\cline { 2 - 3 } & Water heater & 11 \\
\cline { 2 - 3 } Home decoration & 11 \\
\cline { 2 - 3 } & Microwave & 7.5 \\
\cline { 2 - 3 } & Video games & 4 \\
\cline { 2 - 2 } & Printer & 4 \\
\cline { 2 - 2 } & Space heater & 4 \\
\cline { 2 - 2 } & Cooling fan & 4 \\
\cline { 2 - 2 } & Electrical tools (DIY) & 4 \\
\hline
\end{tabular}

Our sampling of 53 households is not enough to demonstrate whether ownership of these appliances is a clear indication of higher economic status. However, we observe that higher proportions of participants who own their residence also own more energy consuming appliances compared to participants who do not. Furthermore, although we found no clear patterns of relationship between education level and appliance ownership, we observed that those with a university degree are more likely to own a computer, a food processor, an iron, a hair clipper, a washing machine and a water heater.

The focus group discussions also revealed how electricity is woven through the lives of the city's residents. In general, people incorporate several interconnected meanings as to why and how they seek modern energy services. For the most part, the themes that emerged revolve around achieving wellbeing and utilitarian goals, appreciating technological advancement and gaining satisfaction from a sense of personal and social progressiveness. Asked to describe what electricity means to them, participants described it as 'an engine to our lives' (Female02, Gulele1)3; a 'lifeline to our economy and home' (Male01, Ledeta2); and 'a guarantor of my safety, security and peace' (Male03, Yeka1). Participants also noted that electricity 'saves time and the forest!' (Male04, Ledeta2) and 'if you can't charge your phone, you can't work' (Male03, Gulele2).

Emotional wellbeing and utilitarian benefits are seen not only in terms of saving time or achieving comfort, but also as signs of a life well lived. The use and usability of electricity were often framed from a perspective of what is at risk of being lost, either due to service interruptions or the tariff change. While access is seen as a sign of progress, power outage is

\footnotetext{
${ }^{3}$ We used this format to anonymise the study participants. The first term 'female 02 ' is an identity we have given the person; the second term, 'Gulele1', refers to the subcity (location of the study) and the number ' 1 ' or ' 2 ' denotes whether the person was from a morning (1) or an afternoon (2) session.
} 
seen as a reversal of those social and economic gains. This is more apparent when participants expressed personal anxiety about their ability to continue to achieve the essential services modern energy affords. While discussing the tariff increase, one participant said: 'We will have no choice but to return to the bygone era when we used to use kerosene for lighting and wood for cooking' (Female01, Kirkos1). An elderly man said: 'As a pensioner, I worry we will have to disconnect ourselves and go backward in our old age' (Male03, Ledeta1). An adequate supply of electricity is also seen as essential for economic growth and to put the country 'on equal footing with advanced nations' (Male01, Ledeta1). Many expressed hope the on-going power projects could materially transform the national economy and their energy conditions. One participant noted:

Once the construction of the dam [GERD] is completed, it will lead to good things. Investment could increase and job creation could grow. Potentially, we could reach a point where we will have access to power for 24 hours with no interruption. (Male02, Kirkos2)

It is clear that for the city residents, the grid has transcended its narrowly defined utilitarian functions. Electricity is deeply intertwined not only with the residents' daily routines, but also with their expectations and questions about their own social and economic participation. To borrow from David Nye's description of life in United States at the end of the twentieth century, consuming power in Addis Ababa has become at once a technical question, an economic field, a political problem and a highly personal matter [65].

\subsection{The cost of unreliable energy services}

Service interruption is a critical factor that prevents grid-connected households from achieving optimal service in Addis Ababa [48]. Households experience two kinds of service interruptions: rolling blackouts and power outages. Rolling blackouts occur in response to demand management: power is shut down intermittently from 6 to 12 hours to overcome energy gaps during certain times of the year and when there is insufficient water in dams to drive electricity generating turbines. Power outage is the second form of service interruption households experience. Outages occur because of a technical problem specific to either a house or cluster of houses, or elsewhere along the distribution network. Besides power outages, households regularly experience fluctuations in voltage affecting the overall quality of supply. Voltage issues from an overloaded electricity system means supply is either too low to operate some appliances or so high that it damages them $[48,49]$. 
In our survey, we found that households appear to be concerned as much about the rising cost of electricity as they are about the deterioration in the quality of service. Nearly 34 per cent of them said they experience service interruption at least twice a week and 40 per cent said two to four times a week. Sixty-two per cent of those surveyed said electricity service provision has worsened in the past 12 months, while about 10 per cent said it has improved. Sixty-three per cent of those surveyed said they worry about the quality of service 'a lot and all the time'. Similarly, 65 per cent said they are concerned about the rising cost of electricity 'a lot and all the time'. A significant number of the respondents (49 per cent) also expressed support for a further tariff increase if the provider improved overall service.

Service interruption affects households in multiple ways. There is the disruption to daily routines, ranging from getting children ready for school to preparing meals and carrying out other household chores. Over 50 per cent of those surveyed said that if they got to choose when the power went out, they would prefer not to lose it in the morning. Damage to property is typical not only from power surges, but also from power outages that at times last for days. Many talked about food rotting in the refrigerator, expressed their concerns about safety when walking at night in the dark, and made clear their apprehensions about the danger exposed electric wires and transformers on street corners. Besides the psychological distress and possible damage to property, there is also the financial cost households incur in the form of additional expenditure on candles, charcoal, firewood and batteries (see also [57]). For those who run small businesses, the cost is particularly high. One participant who owns a hair salon said:

We often lose power at critical times from a work perspective. Holidays like Christmas and Easter are when we make money, but then power goes out on the eve and does not come back for two or three days. During this time, we have no choice but to turn customers away. (Female04, Ledeta1)

Households also sustain costs in terms of time, money and effort as they seek to resolve their service related problems. The FGD participants noted that the problematic aspect of the ordeal associated with service interruption is the uncertainty about when power would be restored. During service interruptions, customers are advised to dial the utility call centre: 905. However, by all accounts, the system is overwhelmed and unable to receive and process all calls. Calls are often unanswered, or requests for maintenance service are not passed on to 
those who can address the problem. According to one study, 44 per cent of the 905 calls customers make are not picked up by the utility [66]. Even after calls are received, it is common for problems to remain unaddressed for days, and, at times, weeks. According to one study, the top three reasons customers call 905 is to 'report a power interruption', to 'follow up on a delayed service repair', and to 'report a fallen pole, damaged cable or burnt transformer' [67]. During a focus group discussion in Kirkos sub-city, one participant shared his experience, saying:

One time when a circuit breaker on our street blew up we had to wait for fifteen days before the repair team came. During this time, every day we called them and every day they said the same thing: 'We will be there tomorrow.' (Male01, Kirkos2)

When call centres fail to deliver results, consumers resort to visiting the utility office in person to appeal directly for resolution. However, many also note that it generally takes multiple visits before people find the right office, staff or information with the information or the solution to their problems. An elderly man in Kirkos said:

When you call they take your information but then nothing happens. When you call back days later, they say 'we have no record of it' and take your information again. It is better to go to their offices [the Utility] in person. The first time you go they might not say yes, the second time they might also not say yes, by the third or fourth time they will send a worker, at least, to come and see the problem. (Male4, Kirkos2)

People also shared the difficulties they faced in navigating institutions and institutional procedures. One man described the ordeal many say they face as follows:

Sometimes you see a problem with your bill and you want to solve it, but then because the utility has many hierarchies you have to start at the bottom. However, at every step the answer you get is the same: 'This does not concern my department.' But then you don't know whom to ask anymore or where else to go, so you give up. (Male04, Yeka1)

If bills, meters and maintenance services are the things of which the customer-service provider relationship are made [22], in Addis Ababa the relationship is fraught with misunderstanding and mistrust. Besides frequent power outages and voltage fluctuations, delayed bill collection and unclear billing and payment procedures contribute to customer frustration $[56,68]$. In our study we observe that dissatisfied with service interruptions, 
delayed repair and maintenance work, and a general lack of clarity, consumers have come to believe that the utility is either incapable or unwilling to meet their needs. Customers extend their wariness across a wider area to question the trustworthiness of the utility employees and wonder if the meter reader is making the number up, or if the maintenance crew are sabotaging the repair work, looking for a bribe. In Gulele sub-city one man asked: 'How can a fuse blow out within hours of them fixing it?' (Male05, Gulele2).

Lack of trust and confidence in the utility, for the most part, also stems from households' limited understanding about the tariff increase and their own energy consumption. Although more than 58 per cent of those surveyed said they understood the tariff change, during the group discussions no one (except for two individuals) was able to tell us how the tariff increase would be rolled out over the next four years. None of the participants seem aware of the changes in how their bills are now computed (from IBT to VDT) and how that change is affecting their consumption-based billing. This fact is important, as consumers are effectively making their energy related decisions in the dark, so to speak. On the other hand, the less informed consumers are, the easier it is for them to assume the worst. In many instances, participants spoke about incidents in which they were convinced that there was a large discrepancy between their perceived consumption and the bill. A few expressed their misgivings about their own energy saving efforts: 'We use charcoal more and more, but we are not seeing any difference on our bills' (Female04, Yeka1) and, 'We no longer turn the lights on in every room, but I don't see any change in what we pay' (Femal04, Kirkos2).

\subsection{Coping with unreliable electricity supply and a tariff increase}

The overall impact of the price increase on household energy consumption behaviour needs to be seen within the context of unreliable supply, inadequate service and consumer scepticism about the utility's ability to behave in a way that is consistent with their energy interests. In Addis Ababa, the effect of a tariff increase on household energy consumption can be placed into two categories - an increase in their use of traditional and solid fuels or a change in their energy use practices - or some combination of the two. Faced with a scarcity of supply or an increase in price, low income households either cut back consumption or switch to using traditional fuels. Middle- and higher- income households tend to either maintain consumption or purchase efficient appliances [11]. 
During focus group discussions, many of the participants reported changes in their daily routines to cut the cost of electricity, while also constantly rearranging their energy use practices in response to service interruptions. A woman in Gulele sub-city said she uses only one electrical appliance at a time: 'If I am baking, I do not turn the television on or charge my phone' (Female04, Gulele2). Essential appliances like cooking stoves and lights are not fully abandoned, but only used when necessary. One woman in Ledeta sub-city said she no longer allows her children to use the electric stove to reheat meals. Households also made a clear connection between the rise in energy prices and the need to reduce consumption by cutting down activities they considered to be a luxury. One woman said: 'My son used to iron his clothes, now we have stopped him from doing that altogether' (Female03, Kirkos2). Many also reported that they have changed when and how often they use electrical appliances. One woman in Gulele said she now runs the washing machine every other week, instead of once a week. Some families said they have stopped the practice of keeping the gate or porch light on overnight. Many also commented that they bake injera after midnight, when the power supply is relatively stable and strong.

The majority of the study participants said they have increased their use of biomass fuels to curb costs; a handful of them said they have acquired solar home systems and rechargeable lanterns. With 89 per cent of the participants identifying electricity as their primary cooking and baking fuel, discussions around the impact of the tariff increase focused on the fact that households have increased their reliance of charcoal and firewood. It is important to make a note of the difference between switching and increasing the use of biomass fuels. Switching suggests a complete shift in practice; however, in reality, fuel stacking is widely common and necessary due to the inherent uncertainty in service delivery [69,70]. Although over 90 per cent of the study participants said electricity is their primary cooking fuel, households never abandoned their charcoal stoves.

We also observe that some households appear to be more resilient in managing their energy needs by embracing a new material culture. A little over 40 per cent of those we interviewed said they use a rechargeable lantern in combination with a candle or a battery-operated torch when the power goes out. A few said they are considering installing solar home systems to mitigate the impact of price increases. Thirteen households said they had acquired smaller solar photovoltaic products, with functions limited to charging phones and lighting. In 
contrast, 30 per cent of the study participants (16 households) said they use a candle and firewood during power outages.

Income is not the only factor that affects a family's capacity to cope with service disruptions and tariff changes. Social and economic competencies appear to be instrumental when it comes to assessing the energy technologies available in the market or acquiring the information necessary to navigate institutional processes. Situations become more severe for those who lack the economic and social capital to manage costs and alleviate the emotional toll it takes. Under normal circumstances, a meter reading error, a delayed bill, a technical failure or an unanswered appeal for repair and maintenance can induce an anxiety and a financial crisis. However, for those vulnerable due to their financial status or other intersection of social characteristics (age, health and employment status), such encounters add to their growing lack of confidence in the system.

Households that lack those competencies (e.g. awareness and resources) not only incur the cost of inconvenience: their capacity to adapt is also affected negatively. To draw examples from the case study we present here, women with no formal education return to cooking with charcoal and firewood and the elderly, whose adoption of technology is relatively low, continue to rely on candles for lighting. Those with pre-existing health conditions also expose themselves to further risks by increasing their reliance on traditional cooking fuels. One woman in Kirkos sub-city commented that those with health issues like blood pressure and diabetes find it particularly difficult to bake injera with firewood and be in a room filled with smoke. Tenants who must adhere to occupancy rules are also limited in their energy options, as they have no control over the material conditions of their homes. For example, some of the study participants noted that after the tariff increase was announced, they had to renegotiate with landlords regarding the types of electrical appliances they can and cannot use. The prepaid meter is celebrated by utilities and policy makers as a reliable cost recovery mechanism. However, for households with unpredictable incomes and can only afford to purchase units in small quantities, the prepaid meter represents a different form of inconvenience. More importantly, where service quality is poor, prepaid customers are particularly vulnerable, as they are being asked to pay in advance for electricity that may not be delivered when needed [71]. 


\section{Conclusions}

The electricity tariff in Ethiopia is considered one of the lowest in the world. However, affordability is a matter of perspective and depends on which side of the fence one sits. This paper looked at the impact of the latest tariff adjustment in Addis Ababa from the perspective of domestic consumers. mWe focused on changes in how households consume electricity (daily routines and practices). Viewing impact from the consumers' perspective allowed us to observe the types of energy services households seek. We took a relational approach to place households' lived experience and the wellbeing aspects of access to modern energy with the quality of service delivery and its governance. Energy services as a concept was used to shift the focus on to the wellbeing and quality of life households achieve. We drew from the literature on energy vulnerability to bring attention to the infrastructural and institutional processes that contribute to the energy insecurity people experience in their homes.

Based on the case study presented, we make some observations: Cost remains an important factor; however, the welfare impact of a tariff increase cannot be seen or understood in isolation from other aspects of service provision that shape how households experience access to modern energy. Households are equally affected and worry about a tariff increase and service inefficiency. In fact, many told us they were willing to support further increases in tariffs if the service were improved. The case study also highlights the intersectionality of energy vulnerability by paying attention to the combined effect of faulty infrastructure, unreliable service, tariff increase and unresponsive institutions. Affordability and reliability are important ingredients to mitigate prospects of domestic energy poverty. However, it is also evident that those with the know-how are better equipped to ride through systemic changes and infrastructural deficiencies, while those that lack the economic and cultural capital necessary to navigate the system bear the brunt.

The energy sector in Ethiopia is undergoing major structural changes. It is not yet clear how the market driven approach, which emphasises a cost-recovery modality, would address the needs of the energy vulnerable in urban areas. One effect of this ongoing transition, which involves big and small changes including the restructuring of tariff rates along with the introduction of prepaid meters and outsourcing of customers relation, is that it is also increasingly shifting the cost to users. Currently, the consumption of grid electricity is subsidised in the form of a lifeline tariff $(50 \mathrm{kWh} / \mathrm{month})$. The premise for this is that low 
income households generally consume smaller quantities of electricity. However, this is not always the case. Depending on their circumstances, such as family size and other household specific requirements, some low-income consumers use more power than the $50 \mathrm{kWh} / \mathrm{month}$ threshold, while for others, the threshold exceeds their consumption level. Moreover, the fact that those confined within the $50 \mathrm{kWh} /$ month limit also experience inadequate service also means they must carry the heavy burden of the additional costs we have outlined in this paper. In addition, and more importantly, the lifeline tariff ceiling assumes that consumers have the necessary information to manage their consumption. However, as demonstrated in this paper, families are making decisions in an energy market where the information asymmetry between the provider and consumers is widespread. Under-informed and uncertain, households are making decisions that appear not logical, in the short run, and possibly harmful, in the long run.

With electricity increasingly becoming an ever more essential part of urban economic and social daily routines, living and working without it is becoming increasingly inconceivable. For those already vulnerable (either due to cost, inferior service delivery or lack of capacity), the impact is not only limited to the time, effort and money involved, but also extends to wellbeing (health, safety), lifestyle and the environment (e.g. cooking with polluting fuel). Thus, while any customer can face detriment due to tariff change, attention needs to be paid to those most in need of support and protection. Policymakers in low- and middle- income countries have many tools they can use to regulate the behaviour of affluent and heavy endusers without harming those that are vulnerable to energy poverty. In Ethiopia, the ongoing restructuring of the energy sector is happening with little effort towards a differentiated analysis of users and their needs. There is some empirical evidence on how differentiated analysis can be used to identify and provide a targeted provision of support to the most vulnerable [72]. Identifying those in need and energy vulnerable will require carefully calibrated policy measures, for which a proper understanding of the situation is necessary [25]. It also depends on the service provider's ability to recognise how the existing system contributes to households' negative experiences. In the short run, service providing institutions could focus on changing the underlying factors that contribute to the problem, such as building communities' trust; improving the quality of service; and re-evaluating the institutional approach to customer care. 
This paper is one attempt to underscore the effect of inadequate service, unreliable supply and a tariff increase on urban households. More studies and empirical evidence are needed to document the phenomenon further and develop a mitigation strategy. This could involve several aspects: (i) a better appreciation of the linkages among institutional procedures, governance approaches and infrastructural deficiencies is relevant to see how some communities are predisposed to experiencing energy poverty; (ii) a realistic assessment could also motivate service providers to support and prioritise policy initiatives that are attentive to the needs and demands of those they serve; and (iii) policies and programmes could be designed to empower consumers to become better at managing their energy needs, while also resolving institutional and procedural barriers to build better community relations. For example, a gesture as basic as an adequate provision of information regarding the duration of a power outage could empower households to plan what measures they might need to take: an important step towards enabling families to maximise their resilience [73]. Seen this way, energy for inclusive growth becomes about finding an optimal combination of infrastructural inputs, service provision, and a governance framework that is receptive to users need. 


\section{References}

[1] A.C. Sadath, R.H. Acharya, Assessing the extent and intensity of energy poverty using Multidimensional Energy Poverty Index: Empirical evidence from households in India, Energy Policy. 102 (2017) 540-550. doi:10.1016/j.enpol.2016.12.056.

[2] C. Harrison, J. Popke, "Because you got to have heat": The networked assemblage of energy poverty in eastern North Carolina, Ann. Assoc. Am. Geogr. 101 (2011) 949-961. doi:10.1080/00045608.2011.569659.

[3] S.R. Khandker, D.F. Barnes, H.A. Samad, Energy Poverty in Rural and Urban India. Are the Energy Poor Also Income Poor?, Policy Res. Work. Pape. 5463 (2010) 1-38.

http://documents.worldbank.org/curated/en/920901468259774557/pdf/WPS5463.pdf.

[4] R. Day, G. Walker, N. Simcock, Conceptualising energy use and energy poverty using a capabilities framework, Energy Policy. 93 (2016) 255-264. doi:10.1016/j.enpol.2016.03.019.

[5] J. Modi, Vijay, McDade, S., Lallement, D., Saghir, Energy Services for the Millennium Development Goals, 2005.

[6] S. Bouzarovski, Energy Poverty: (Dis)Assembling Europe's Infrastructural Divide, 2017. doi:10.1007/978-3-319-69299-9.

[7] R. Haas, J. Watson, W. Eichhammer, Transitions to sustainable energy systems- Introduction to the energy policy special issue, Energy Policy. 36 (2008) 4009-4011.

[8] G. Kalt, D. Wiedenhofer, C. Görg, H. Haberl, Conceptualizing energy services: A review of energy and well-being along the Energy Service Cascade, Energy Res. Soc. Sci. 53 (2019) $47-$ 58. doi:10.1016/j.erss.2019.02.026.

[9] M. Bazilian, P. Nussbaumer, C. Eibs-Singer, A. Brew-Hammond, V. Modi, B. Sovacool, V. Ramana, P.K. Aqrawi, Improving Access to Modern Energy Services: Insights from Case Studies, Electr. J. 25 (2012) 93-114. doi:10.1016/j.tej.2012.01.007.

[10] J. Stephenson, B. Barton, G. Carrington, A. Doering, R. Ford, D. Hopkins, R. Lawson, A. McCarthy, D. Rees, M. Scott, P. Thorsnes, S. Walton, J. Williams, B. Wooliscroft, The energy cultures framework: Exploring the role of norms, practices and material culture in shaping energy behaviour in New Zealand, Energy Res. Soc. Sci. 7 (2015) 117-123. doi:10.1016/j.erss.2015.03.005.

[11] L. Lutzenhiser, Social and behavioural aspects of energy use, Annu. Rev. Energy Environ. 18 (1993) 247-289. doi:10.1111/aman.12366.

[12] S. Bouzarovski, S. Petrova, S. Tirado-Herrero, From Fuel Poverty to Energy Vulnerability: The Importance of Services, Needs and Practices., SSRN Electron. J. 2014 (2016). doi:10.2139/ssrn.2743143.

[13] S. Bouzarovski, S. Petrova, A global perspective on domestic energy deprivation: Overcoming the energy poverty-fuel poverty binary, Energy Res. Soc. Sci. 10 (2015) 31-40. doi:10.1016/j.erss.2015.06.007.

[14] S. Bouzarovski, Understanding Energy Poverty, Vulnerability and Justice, in: Energy Poverty (Dis)Assembling Eur. Infrastructural Divid., Springer International Publishing, Cham, 2018: pp. 9-39. doi:10.1007/978-3-319-69299-9_2.

[15] K. Jenkins, D. McCauley, R. Heffron, H. Stephan, R. Rehner, Energy justice: A conceptual review, Energy Res. Soc. Sci. 11 (2016) 174-182. doi:10.1016/j.erss.2015.10.004.

[16] S. Bouzarovski, H. Thomson, Energy Vulnerability in the Grain of the City: Toward Neighborhood Typologies of Material Deprivation, Ann. Am. Assoc. Geogr. 108 (2018) 695717. doi:10.1080/24694452.2017.1373624.

[17] R.S. Liévanos, C. Horne, Unequal resilience: The duration of electricity outages, Energy Policy. 108 (2017) 201-211. doi:10.1016/j.enpol.2017.05.058.

[18] K. Tierney, The Social Roots of Risk: Producing Disasters, Promoting Resilience, Stanford University Press, Sanford, California, 2014.

[19] O.H. Fjeldstad, What has trust got to do with it? Non-payment of service charges in local authorities in South Africa, Work. Pap. - Chr. Michelsen Inst. (2003) 1-26.

[20] B.K. Sovacool, What are we doing here? Analyzing fifteen years of energy scholarship and 
proposing a social science research agenda, Energy Res. Soc. Sci. 1 (2014) 1-29.

doi:10.1016/j.erss.2014.02.003.

[21] K. Stenner, E.R. Frederiks, E. V. Hobman, S. Cook, Willingness to participate in direct load control: The role of consumer distrust, Appl. Energy. 189 (2017) 76-88.

doi:10.1016/j.apenergy.2016.10.099.

[22] T. Winther, Electricity theft as a relational issue: A comparative look at Zanzibar, Tanzania, and the Sunderban Islands, India, Energy Sustain. Dev. 16 (2012) 111-119.

doi:10.1016/j.esd.2011.11.002.

[23] S. Buzar, When homes become prisons: The relational spaces of postsocialist energy poverty, Environ. Plan. A. 39 (2007) 1908-1925. doi:10.1068/a38298.

[24] S. Buzar, The "hidden" geographies of energy poverty in post-socialism: Between institutions and households, Geoforum. 38 (2007) 224-240. doi:10.1016/j.geoforum.2006.02.007.

[25] P. Nussbaumer, M. Bazilian, V. Modi, Measuring energy poverty: Focusing on what matters, Renew. Sustain. Energy Rev. 16 (2012) 231-243. doi:10.1016/j.rser.2011.07.150.

[26] M. Bhatia, N. Angelou, Capturing the multi-dimentionality of energy access, Washington DC, 2014.

[27] J. Goldemberg, T.B. Johansson, A.K.N. Reddy, R.H. Williams, "Basic needs and much more with one kilowatt per capita," Ambio. 14 (1985) 190-200.

[28] B.K. Sovacool, C. Cooper, M. Bazilian, K. Johnson, D. Zoppo, S. Clarke, J. Eidsness, M. Crafton, T. Velumail, H.A. Raza, What moves and works: Broadening the consideration of energy poverty, Energy Policy. 42 (2012) 715-719. doi:10.1016/j.enpol.2011.12.007.

[29] B.K. Sovacool, Conceptualizing urban household energy use: Climbing the "Energy Services Ladder," Energy Policy. 39 (2011) 1659-1668. doi:10.1016/j.enpol.2010.12.041.

[30] A. Sen, Inequality Reexamined, Harvard University, Cambridge, MA, 1992.

[31] C. Villalobos, C. Chavez, A. Uribe, Energy poverty measures and the identification of the energy poor: A comparision between the utilitarian and multidimentional approaches, Capab. Dilemma Oper. Poverty Assessment,. (2019) 0-35.

[32] L.I. Brand-Correa, J.K. Steinberger, A Framework for Decoupling Human Need Satisfaction From Energy Use, Ecol. Econ. 141 (2017) 43-52. doi:10.1016/j.ecolecon.2017.05.019.

[33] S. Petrova, Encountering energy precarity: Geographies of fuel poverty among young adults in the UK, Trans. Inst. Br. Geogr. 43 (2018) 17-30. doi:10.1111/tran.12196.

[34] L. Middlemiss, R. Gillard, Fuel poverty from the bottom-up: Characterising household energy vulnerability through the lived experience of the fuel poor, Energy Res. Soc. Sci. 6 (2015) 146-154. doi:10.1016/j.erss.2015.02.001.

[35] L. Middlemiss, P. Ambrosio-Albalá, N. Emmel, R. Gillard, J. Gilbertson, T. Hargreaves, C. Mullen, T. Ryan, C. Snell, A. Tod, Energy poverty and social relations: A capabilities approach, Energy Res. Soc. Sci. 55 (2019) 227-235. doi:10.1016/j.erss.2019.05.002.

[36] D.F. Barnes, The Urban Household Energy Transition, Urban Househ. Energy Transit. (2010). doi:10.4324/9781936331000.

[37] S. Bouzarovski, S. Petrova, M. Kitching, J. Baldwick, Precarious domesticities: energy vulnerability among urban young adults, Energy Justice a Chang. Clim. Soc. Equity a Chang. Clim. (2013) 30-45.

[38] R. Singh, X. Wang, J.C. Mendoza, E.K. Ackom, Electricity (in)accessibility to the urban poor in developing countries, Wiley Interdiscip. Rev. Energy Environ. 4 (2015) 339-353. doi:10.1002/wene.148.

[39] V. Castán Broto, I. Baptista, J. Kirshner, S. Smith, S. Neves Alves, Energy justice and sustainability transitions in Mozambique, Appl. Energy. 228 (2018) 645-655. doi:10.1016/j.apenergy.2018.06.057.

[40] I. Baptista, "We live on estimates": Everyday Practices of Prepaid Electricity and the Urban Condition in Maputo, Mozambique, Int. J. Urban Reg. Res. 39 (2016) 1004-1019. doi:https://doi.org/10.1111/1468-2427.12314.

[41] V. Jacome, I. Ray, The prepaid electric meter: Rights, relationships and reification in Unguja, Tanzania, World Dev. 105 (2018) 262-272. doi:10.1016/j.worlddev.2018.01.007.

[42] S. Graham, N. Thrift, Out of Order: Understanding Repair and Maintenance, Theory, Cult. Soc. 24 (2007) 1-25. doi:10.1177/0263276407075954. 
[43] W. Bank, Second Ethiopia Growth and Competitiveness Programmatic DPF, Washington DC, 2020.

[44] R. Lefort, Free market economy, "Developmental State" and party-state hegemony in Ethiopia, J. Moden African Stud. 50 (2012) 681-706. doi:10.1017/S0022278X12000389.

[45] S. Vaughan, K. Tronvoll, The Culture of Power in Contemporary Ethiopian Political Life (review), Afr. Stud. Rev. 48 (2003). doi:10.1353/arw.2005.0053.

[46] A.T. Shiferaw, O.J. Klakegg, T. Haavaldsen, Governance of Public Investment Projects in Ethiopia, Proj. Manag. J. 43 (2012) 52-69. doi:10.1002/pmj.21280.

[47] B. Tarekegne, Just electrification: Imagining the justice dimensions of energy access and addressing energy poverty, Energy Res. Soc. Sci. 70 (2020) 101639. doi:10.1016/j.erss.2020.101639.

[48] G. Padam, D. Rysankova, E. Portale, B. Koo, S. Keller, G. Fleurantin, Ethiopia - Beyond Connections : Energy access diagnostic report based on the Multi-Tier Framework, Washington DC, 2018.

[49] T.H. Meles, Impact of power outages on households in developing countries: Evidence from Ethiopia, Energy Econ. 91 (2020) 104882. doi:10.1016/j.eneco.2020.104882.

[50] L. Smith, The murky waters of the second wave of neoliberalism: Corporatization as a service delivery model in Cape Town, Geoforum. 35 (2004) 375-393. doi:10.1016/j.geoforum.2003.05.003.

[51] M. Kojima, C. Trimble, Making Power Affordable for Africa and Viable for Its Utilities, Washington DC, 2016.

[52] M. Girma, Electric tariff increase sends shockwave through consumers, Addis Fortune. (2019).

[53] Ethiopian Energy Authority, Tariff Guideline and Methodology for Grid Power Supply, 2018.

[54] The World Bank, Addis ababa: Enhancing Urban Resilience, (2015). http://www.ncbi.nlm.nih.gov/pubmed/23033339.

[55] CSA, Welfare Monitoring Survey, Addis Ababa, 2016.

[56] UN-Habitat, The State Of Addis Ababa, 2017. http://etd.aau.edu.et/dspace/handle/123456789/2372.

[57] T.H. Meles, Power outages, increasing block tariffs and billing knowledge, University of Gothenburg, 2017.

[58] A. Asfaw, Sustainable Household Energy for Addis Ababa, Ethiopia, J. Sustain. Dev. 8 (2012) 1-11. http://www.consiliencejournal.org/index.php/consilience/article/viewFile/252/110.

[59] C.S. Agency, The 2015/16 Ethiopian Household Consumption - Expenditure (HCE) Survey, Results For: Addis Ababa City Administration, Stat. Bull. (2018) 325.

[60] A.L. Strauss, Qualitative Analysis for Social Scientists, Cambridge University Press, Cambridge, 1987.

[61] L. Larsen, K. Yeshitela, T. Mulatu, S. Seifu, H. Desta, The impact of rapid urbanization and public housing development on urban form and density in Addis Ababa, Ethiopia, Land. 8 (2019). doi:10.3390/land8040066.

[62] R. Heltberg, Fuel switching: evidence from eight developing countries, Energy Econ. 26 (2004) 869-887.

[63] R. Khalid, M. Sunikka-Blank, Homely social practices, uncanny electricity demands: Class, culture and material dynamics in Pakistan, Energy Res. Soc. Sci. 34 (2017) 122-131. doi:10.1016/j.erss.2017.06.038.

[64] E. Shove, Consumption, Everyday life and sustainability chapter one, (2003).

[65] D. Nye, Consuming Power: A social history of American Energies, 3rd ed., MIT Press, Cambridge, MA, 2001.

[66] B. Ayele, Power Interruptions OUtrage Businesses, Residents, Addis Fortune. (2018). https://addisfortune.net/columns/power-interruptions-outrage-businesses-residents/.

[67] M. Yihdego, Assessment of factors affecting incoming calls at Ethiopia Electric Utility Call Center, St. Mary's University College, 2018.

[68] D.F. Barnes, R. Golumbeanu, W. Bank, I. Diaw, Beyond Electricity Access: Output-Based Aid and Rural Electrification in Ethiopia, (2016) 148. doi:10.13140/RG.2.2.16406.24643.

[69] O. Masera, B.S. Taylor, D.M. Kammen, From linear fuel switching to multiple cooking strategies, World Dev. 28 (2000) 2083-2103. 
[70] Y. Alem, A.D. Beyene, G. Kohlin, A. Mekonnen, Modeling household cooking fuel choice: A panel multinomial logit approach, Energy Econ. 59 (2016) 129-137.

[71] M. Kojima, X. Zhou, J.J. Han, J. de Wit, R. Bacon, C. Trimble, Who Uses Electricity in SubSaharan Africa?, World Bank Policy Res. Work. Pap. 7889. (2016).

http://documents.worldbank.org/curated/en/967821470756082684/pdf/WPS7789.pdf.

[72] SEforALL, Energy Safety Nets: Using Social Assistance Mechanisms to Close Affordability Gaps for the Poor, Vienna, 2020. doi:10.1557/mrs.2016.29.

[73] D.A. Ghanem, S. Mander, C. Gough, "I think we need to get a better generator": Household resilience to disruption to power supply during storm events, Energy Policy. 92 (2016) 171180. doi:10.1016/j.enpol.2016.02.003. 